\title{
ANALISIS KOMPETENSI PEDAGOGIK GURU MATA PELAJARAN GEOGRAFI SEKOLAH MENENGAH ATAS (SMA) SEBAGAI PELAKSANA KURIKULUM 2013 DI KABUPATEN KETAPANG
}

\author{
Norsidi $^{1}$, Paiman ${ }^{2}$ \\ ${ }^{1,2}$ Program Studi Pendidikan Geografi \\ Fakultas Ilmu Pendidikan dan Pengetahuan Sosial IKIP PGRI Pontianak \\ Jalan Ampera Nomor 88 Pontianak - 78116, Telepon (0561) 748219 Fax. (0561) 589855 \\ ${ }^{1}$ Alamat e-mail: habibisukma1991@gmail.com
}

\begin{abstract}
Abstrak
Penelitian ini bertujuan mengetahui kemampuan pedagogik guru mata pelajaran geografi Sekolah Menengah Atas (SMA) dalam mengimplementasikan kurikulum 2013 di Kabupaten Ketapang. Teknik pengambilan sampel menggunakan purposive sampling. Metode yang digunakan dalam penelitin ini adalah kuantitatif deskriptif. Data yang digunakan berupa data primer yang dikumpulkan melalui angket. Analisis data menggunakan rata-rata dan persentase skor. Hasil penelitian ini menunjukkan bahwa kemampuan pedagogik guru pada indikator: a) memahami karateristik peserta didik dari aspek fisik, moral, spiritual, sosial, kultural emosional, dan intelektual dikategorikan dengan rata-rata nilai 3,06\% baik; b) menguasai teori belajar dan prinsip-prinsip pembelajaran dikategorikan baik dengan rata-rata nilai $3,25 \%$ baik; c) mengembangkan kurikulum terkait mata pelajaran yang diampu dikategorikanbaik dengan rata-rata nilai $3,20 \%$ baik; d) menyelenggarakan pembelajaran yang mendidik dengan rata-rata nilai 3,03\% baik; e) memanfaatkan teknologi informasi dan komunikasi dengan rata-rata nilai 2,76\% kurang mampu; f) mengembangkan peserta didik untuk mengaktualisasikan berbagai potensi yang dimilikinya dengan rata-rata nilai 3,21 baik; g) berkomunikasi secara efektif, empatik, dan santun dengan rata-rata nilai 3,21 baik; h) menyelenggarakan penilaian dan evaluasi hasil belajar dengan rata-rata nilai 3,43 baik; i) Memanfaatkan hasil penilaian dan evaluasi 2,78 baik; j) melakukan tindakan reflektif dengan rata-rata nilai 3,00 baik.
\end{abstract}

Kata kunci: Kompetensi Pedagogik, Kurikulum 2013

\section{Abstract}

This study aims to determine the pedagogical ability of geography teachers at the high school in implementing the 2013 curriculum in Ketapang Regency. The sampling technique used purposive sampling. The method used in this research were descriptive quantitative. The data used in the form of primary data that collected through questionnaires. Data analysis uses average and percentage scores. The results of this research indicate that the pedagogical abilities of teachers on indicators: a) understand the characteristics of students from the physical, moral, spiritual, social, cultural, emotional and intellectual aspects categorized with an average score of $3.06 \%$ goog; b) mastering learning theory and learning principles are categorized as good with an average value of $3.25 \%$ good; c) developing a curriculum related to subjects that are categorized as good with an average value of $3.20 \%$ good; d) organizing educational learning with an average score of $3.03 \%$ good; e) utilizing information and communication technology with an average value of $2.76 \%$ less capable; f) develop students to actualize various potentials they have with an average value of 3.21 good; g) communicate effectively, empathetically, and politely with an average grade of 3.21 good; h) hold an assessment and evaluation of learning outcomes with an average grade of $3.43 \mathrm{good} ; i)$ Utilizing the results of 
evaluation and evaluation 2.78 good; $j$ ) do reflective action with an average value of 3.00 good.

Keywords: Pedagogic Competence, 2013 Curriculum

\section{PENDAHULUAN}

Kurikulum merupakan pondasi untuk mengatur pelaksanaan proses kegiatan belajar mengajar antara guru dan siswa dalam sistem pendidikan. Kurikulum merupakan pondasi untuk mengatur pelaksanaan proses kegiatan belajar mengajar dalam pelaksanaan sistem pendidikan yang ada di Inondesia (Norsidi, 2018). Konsep kurikulum 2013 yang dibuat oleh para ahli pendidikan yang ada di Indonesia sengaja untuk mempersiapkan dan membentuk kualitas sumberdaya manusia yang memiliki kemampuan hidup, baik sebagai insan pribadi yang cendekia, taat beragama, produktif, aktif, inovatif dan berkreativitas tinggi. serta mampu bersaing dan memberikan kontribusi pada kehidupan bermasyarakat, berbangsa, bernegara, dan pada peradaban dunia. Bila kurikulum tidak diubah, lulusan yang dihasilkan adalah lulusan usang yang tidak terserap di dunia kerja (Kemendikbud, 2012).

Untuk dapat meningkatkan kualitas pendidikan agar sesuai dengan keinginan, tuntutan dan harapan masyarakat maka pemerintah harus berupaya dan berperan semaksimal mungkin untuk melakukan evaluasi dan revisi pelaksanaan kurikulum setiap lima tahun sekali dan melakukan pergantian kurikulum setiap sepuluh tahun sekali sesuai dengan kebutuhan. Begitu pula yang terjadi pada saat ini yaitu adanya perubahan Kurikulum Tingkat Satuan Pendidikan (KTSP) menjadi Kurikulum 2013 (Herliani \& Dhiniaty, 2015). Pengembangan kurikulum 2013 karena adanya tantangan internal maupun tantangan eksternal (Kemendikbud 2013a).

Saat ini pemerintah melalui Keputusan Direktur Jenderal Pendidikan Dasar dan Menengah Nomor: 374/KEP/D/KR/2016 pada tanggal 11 Juli 2016 perubahan atas keputusan Direktur Jenderal Pendidikan Dasar dan Menengah Nomor 305/KEP/D/KR/2016 Tentang Penetapan Satuan Pendidikan Pelaksana Kurikulum 2013 telah menunjuk sebanyak 2049 tingkat sekolah menengah atas/sederajat negeri maupun swasta di berbagai kota dan kabupaten yang ada di 
seluruh provinsi wilayah Indonesia yang dianggap siap melaksanakan kurkulum 2013 ke dalam mata pelajaran.

Kabupaten Ketapang Provinsi Kalimantan Barat salah satu bagian dari wilayah Indonesia yang bebeberapa sekolah ditunjuk sebagai pelaksana Kurikulum 2013 khusunya tingkat Sekolah Menengah Atas (SMA). Pemerintah dalam mensukseskan kurikulum 2013 telah berupaya banyak untuk mensosialisasikan dan memberikan pelatihan dalam memberikan gambaran kepada seluruh jenjang pada setiap elemen pendidikan terkait pelaksanaan kurikulum 2013. Pemerintah juga menyediakan rancangan dalam bentuk dokumen kurikulum 2013 untuk memudahkan para guru dalam memahami dan melaksanakan yang bisa di akses melalui internet. Rancangan kurikulum yang terdapat pada Bahan Uji Publik Kurikulum 2013 memiliki komponen-komponen pengembangan kurikulum yang terdiri dari komponen tujuan, komponen isi, komponen metode, dan komponen evaluasi (Kusuma, 2013).

Konsep kesamaan antara SMA dan SMK dikembangkan dengan kurikulum yang terdiri atas kelompok mata pelajaran wajib dan mata pelajaran Pilihan.Mata pelajaran wajib sebanyak 9 (Sembilan) mata pelajaran dengan beban belajar 18 jam per minggu.Mata pelajaran pilihan terdiri atas pilihan akademik (SMA) serta pilihan akademik dan vokasional (SMK). Beban belajar di tingkat SMA untuk kelas X, XI, dan XII masing-masing 43 jam belajar per minggu. Untuk mengikuti satu jam pelajaran selama 45 menit.Kompetensi Dasar mata pelajaran wajib memuat kemampuan dasar yang sama antara mereka yang belajar di SMA dan SMK. Untuk mata pelajaran yang di SMA tersedia pilihan kelompok peminatan dan siswa bebas untuk memilih sesuai dengan kelompok peminatan. Kurikulum terdahulu yang semula IPA, IPS dan Bahasa sekarang berubah menjadi Matematika dan Sains, Sosial, dan Bahasa.

Untuk mencapai pelaksanaan kurikulum sesuai dengan harapan pemerintah, guru di tuntut untuk selalu profesional, cerdas, inovatif dan kreatif. Begitu pula dengan guru mata pelajaran geografi tingkat Sekolah Menengah Atas (SMA) tidak hanya dituntut memiliki kompetensi profesional, namun juga harus memiliki kompetensi pedagogik, sosial, dan kepribadian. Baiknya proses 
pembelajaran dan hasil belajar peserta didik sangat ditentukan oleh peranan dan kompetensi guru. Kompeten guru yang baik akan tercipta suasana lingkungan belajar yang efektif dan mampu mengelola kelas sehingga peserta didik mampu mencapai hasil belajar yang maksimal. Untuk itu kompetensi pedagogik guru perlu diketahui karena berkaitan dengan pengembangan kurikulum serta proses pelaksanaan dalam pembelajaran.

Kompetensi pedagogik guru yang baik akan berdampak pada proses kegiatan pembelajaran yang dinamis, disenangi siswa, dan mampu menyerap tinggi dalam meningkatkan konsentrasi belajar siswa sesuai dengan kompetensi, karakteristik dan kebutuhan siswa dalam belajar. Kompetensi pedagogik guru merupakan kemampuan guru dalam pengelolaan pembelajaran yang meliputi pemahaman wawasan atau landasan kependidikan keilmuan sehingga memiliki keahlian secara akademik dan intelektual (Feralys, 2015). Kemampuan pedagodik guru yang berkompeten akan melahirkan pembelajar yang mencintai proses pembelajaran yang memahami arti penting belajar untuk masa depan.

Kompetensi pedagogik yang dituangkan di dalam Peraturan Menteri Pendidikan Nasional Nomor 16 Tahun 2007 tentang Standar Kompetensi Guru yang mencakup: (1) Menguasai karakteristik Belajar dari aspek fisik, moral, spiritual, sosial, kultural, emosional, dan intelektual; (2) Menguasai teori belajar dan prinsip-prinsip pembelajaran yang mendidik; (3) Mengembangkan kurikulum yang terkait dengan mata pelajaran yang diampu; (4) Menyelenggarakan pembelajaran Yang mendidik; (5) Memanfaatkan teknologi informasi dan komunikasi untuk kepentingan pembelajaran; (6) Memfasilitasi pengembangan potensi Belajar untuk mengaktualisasikan berbagai potensi yang dimiliki; (7) Berkomunikasi secara efektif, empatik, dan santun dengan Belajar; (8) Menyelenggarakan penilaian dan evaluasi proses dan hasil belajar; (9) Memanfaatkan hasil penilaian dan evaluasi untuk kepentingan pembelajaran; (10) Melakukan tindakan refleksi untuk peningkatan kualitas pembelajaran (Feralys, 2015).

Kegiatan guru dalam prakteknya tingkat Sekolah Menengah Atas (SMA) yang telah ditunjuk sebagai pelaksana kurikulum 2013 di Kabupaten Ketapang, 
ditemukan masih banyak guru khususnya pada mata pelajaran geografi belum siap dalam menghadapi revolusi kurikulum ini. Kompetensi pedagogik guru pemegang mata pelajaran geografi yang belum begitu baik menjadi faktor penghambat dalam mengimplementasikan Kurikulum 2013 ke dalam sebuah mata pelajaran. Kondisi yang seperti ini harus menjadi pemerhati pendidikandankhususnya pemerintahdaerahKabupaten Ketapang untuk meningkatkan mutu kualitas pendidikan.Kondisi dan permasalahan yang muncul dalam pelaksanaan kurikulum 2013 dimana kompetensi guru yang belum memahami dengan baik berkenaan dengan pelaksanaan kurikulum 2013 khususnya dalam tahap pelaksanaan pembelajaran (Herliani \& Dhiniaty, 2015).

Kurikulum 2013 merupakan kurikulum yang baru diterapkan oleh para guru dalam pelaksanaan pembelajaran yang ada di Kabupaten Ketapang. Hal ini tentunya, butuh penyesuaian dan persiapan yang matang untuk menghadapi berbagai persoalan dan tantangan dalam implementasinya. Guru merupakan unsur dominan dalam proses pendidikan, sehingga kualitas pendidikan banyak ditentukan oleh kualitas pendidik dalam menjalankan peran dan tugasnya di masyarakat (Mustofa, 2007). Keberhasilan dari suatu kurikulum yang ingin dicapai sangat bergantung pada faktor kemampuan yang dimiliki oleh seorang guru (Uno, 2009). Para guru mata pelajaran geografi perlu meningkatkan kompetensi pedagogik karena berkaitan denganpengembangan kurikulum yang secara berkelanjutan dalam pelaksanaan pembelajaran. Kompetensi pedagogik ini menuntut seorang guru untuk bisa memahami karakteristik peserta didik agar pendidikan karakter dapat diterapkan dalam setiap proses pembelajaran.

\section{METODE}

Metode yang digunakan dalam penelitian ini adalah metode deskriptif dengan pendekatan kuantitatif yaitu menggunakan perhitungan-perhitungan angka untuk menganalisis kompetensi pedagogik guru.Penelitian deskriptif adalah penelitian yang tidak bermaksud menguji hipotesis tetapi hanya menggambarkan seperti apa adanya tentang suatu variabel, gejala atau keadaan.(Suharsimi, 2006). Populasi penelitian ini seluruh guru mata pelajaran geografi tingkat Sekolah 
Menengah Atas (SMA) Kabupaten Ketapang yang menerapkan Kurikulum 2013. Teknik pengambilan sampel yang digunakan dalam penelitian ini menggunakan purposive sampling yang artinya sampel dipilih berdasarkan pada ciri atau karakteristik dan pertimbangan-pertimbangan berdasarkan tujuan penelitian (Dantes, 2012). Sampel yang dipilih berdasarkan pertimbangan tertentu tujuan penelitian yaitu untuk mengukur kemampuan pedagogik guru mata pelajaran geografi yang mengimplementasikan kurikulum 2013 pada jenjang Sekolah Menengah Atas (SMA) di Kabupaten Ketapang. Data yang digunakan berupa data primer yang dikumpulkan melalui kuesioner atau angket tertutup. Analisis data yang digunakan melalui hitung rata-rata dan persentase skor.

\section{HASIL DAN PEMBAHASAN}

Memahami karakteristik peserta didik dari aspek fisik, moral, spiritual, sosial, kultural, emosional, dan intelektual

Indikator pertama mengenai karakteristik peserta didik dari aspek fisik, moral, spiritual, sosial, kultural, emosional, dan intelektual dapat dikatakan dengan hasil sebagai berikut:

Tabel 1. Rekap Jawaban Kuesioner Indikator 1

Memahami karakteristik peserta didik dari aspek fisik, moral, spiritual, sosial, kultural, emosional, dan intelektual

\begin{tabular}{cccccc}
\hline Item & TB & KB & B & SB & Mean \\
\hline AA1 & $0(0 \%)$ & $1(9.1 \%)$ & $8(72.7 \%)$ & $2(18.2 \%)$ & 3.09 \\
\hline AA2 & $0(0 \%)$ & $0(0 \%)$ & $8(72.7 \%)$ & $3(27.3 \%)$ & 3.27 \\
\hline AA3 & $0(0 \%)$ & $5(45.5 \%)$ & $3(27.3 \%)$ & $3(27.3 \%)$ & 2.82 \\
\hline AA4 & $0(0 \%)$ & $0(0 \%)$ & $8(72.7 \%)$ & $3(27.3 \%)$ & 3.27 \\
\hline AA5 & $0(0 \%)$ & $0(0 \%)$ & $9(81.8 \%)$ & $2(18.2 \%)$ & 3.18 \\
\hline AA6 & $0(0 \%)$ & $0(0 \%)$ & $9(81.8 \%)$ & $2(18.2 \%)$ & 3.18 \\
\hline AA7 & $0(0 \%)$ & $5(45.5 \%)$ & $5(45.5 \%)$ & $1(9.1 \%)$ & 2.64 \\
\hline Total & & & & & 3.06
\end{tabular}

Keterangan: AA adalah Kode Item Pertanyaan
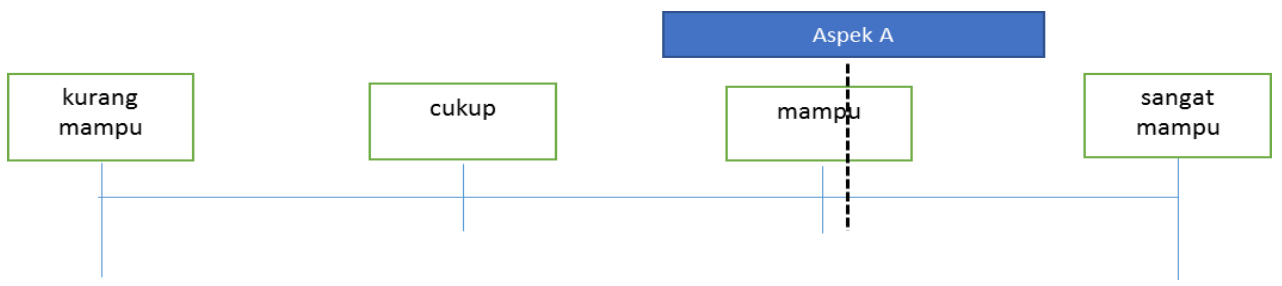


\section{Gambar 1. Diagram Kemampuan Guru Pada Indikator 1}

Item pertanyaan AA1 mempunyai rata-rata 3.09, item pertanyaan AA2 mempunyai rata-rata 3.27 , item pertanyaan AA3 mempunyai rata-rata 2.82 , item pertanyaan AA4 mempunyai rata-rata 3.27, item pertanyaan AA5 mempunyai rata-rata 3.18, item pertanyaan AA6 mempunyai rata-rata 3.18, item pertanyaan AA7 mempunyai rata-rata 2.64. Secara memiliki nilai rata-rata sebesar 3.06 yang berarti dikategorikan baik.

\section{Menguasai teori belajar dan prinsip-pronsip pembelajaran yang mendidik}

Hasil penelitian untuk indikator kedua mengenai penguasaan teori belajar dan prinsip pembelajaran dengan hasil sebagai berikut:

Tabel 2. Rekap Jawaban Kuesioner Indikator 2

\begin{tabular}{cccccc}
\hline \multicolumn{6}{c}{ Menguasai teori belajar dan prinsip-pronsip pembelajaran yang mendidik } \\
\hline Item & TB & KB & B & SB & Mean \\
\hline BB1 & $0(0 \%)$ & $0(0 \%)$ & $9(81.8 \%)$ & $2(18.2 \%)$ & 3.18 \\
\hline BB2 & $0(0 \%)$ & $0(0 \%)$ & $8(72.7 \%)$ & $3(27.3 \%)$ & 3.27 \\
\hline BB3 & $0(0 \%)$ & $1(9.1 \%)$ & $7(63.6 \%)$ & $3(27.3 \%)$ & 3.18 \\
\hline BB4 & $0(0 \%)$ & $0(0 \%)$ & $9(81.8 \%)$ & $2(18.2 \%)$ & 3.18 \\
\hline BB5 & $0(0 \%)$ & $0(0 \%)$ & $9(81.8 \%)$ & $2(18.2 \%)$ & 3.18 \\
\hline BB6 & $0(0 \%)$ & $0(0 \%)$ & $8(72.7 \%)$ & $3(27.3 \%)$ & 3.27 \\
\hline BB7 & $0(0 \%)$ & $1(9.1 \%)$ & $8(72.7 \%)$ & $2(18.2 \%)$ & 3.09 \\
\hline BB8 & $0(0 \%)$ & $2(18.2 \%)$ & $8(72.7 \%)$ & $1(9.1 \%)$ & 2.91 \\
\hline BB9 & $0(0 \%)$ & $0(0 \%)$ & $5(45.5 \%)$ & $6(54.5 \%)$ & 3.55 \\
\hline BB10 & $0(0 \%)$ & $0(0 \%)$ & $4(36.4 \%)$ & $7(63.6 \%)$ & 3.64 \\
\hline Total & & & & & 3.25
\end{tabular}

Keterangan: BB adalah Kode Item Pertanyaan
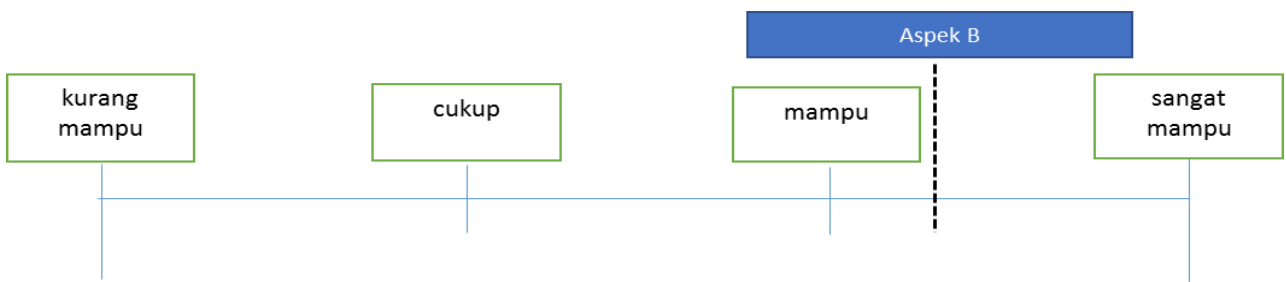

Gambar 2. Diagram Kemampuan Guru Pada Indikator 2

Item pertanyaan BB1 mempunyai rata-rata 3.18 , item pertanyaanBB2 mempunyai rata-rata 3.27 , item pertanyaan $\mathrm{BB} 3$ mempunyai rata-rata 3.18 , item pertanyaan BB4 mempunyai rata-rata 3.18, item pertanyaan BB5 mempunyai rata- 
rata 3.18, item pertanyaan BB6 mempunyai rata-rata 3.27, item pertanyaan BB7 mempunyai rata-rata 3.09, item pertanyaan BB8 mempunyai rata-rata 2.91, item pertanyaan BB9 mempunyai rata-rata 3.55, item pertanyaan BB10 mempunyai rata-rata 3.64. Secara keseluruhan memiliki rata-rata sebesar 3.25 yang berarti dikategorikan baik.

\section{Mengembangkan kurikulum yang terkait dengan mata pelajaran yang diampu}

Hasil penelitian indikator 3 yakni mengenai pengembangan kurikulum terkait mata pelajaran yang diampu sebagai berikut:

Tabel 3. Rekap Jawaban Kuesioner Indikator 3

Mengembangkan kurikulum yang terkait dengan mata pelajaran yang diampu

\begin{tabular}{cccccc}
\hline Item & TB & KB & B & SB & Mean \\
\hline CC1 & $1(9.1 \%)$ & $0(0 \%)$ & $6(54.5 \%)$ & $4(36.4 \%)$ & 3.18 \\
\hline CC2 & $0(0 \%)$ & $0(0 \%)$ & $6(54.5 \%)$ & $5(45.5 \%)$ & 3.45 \\
\hline CC3 & $0(0 \%)$ & $0(0 \%)$ & $8(72.7 \%)$ & $3(27.3 \%)$ & 3.27 \\
\hline CC4 & $0(0 \%)$ & $0(0 \%)$ & $8(72.7 \%)$ & $3(27.3 \%)$ & 3.27 \\
\hline CC5 & $0(0 \%)$ & $0(0 \%)$ & $8(72.7 \%)$ & $3(27.3 \%)$ & 3.27 \\
\hline CC6 & $0(0 \%)$ & $0(0 \%)$ & $8(72.7 \%)$ & $3(27.3 \%)$ & 3.27 \\
\hline CC7 & $0(0 \%)$ & $0(0 \%)$ & $7(63.6 \%)$ & $4(36.4 \%)$ & 3.36 \\
\hline CC8 & $0(0 \%)$ & $0(0 \%)$ & $7(63.6 \%)$ & $4(36.4 \%)$ & 3.36 \\
\hline CC9 & $1(9.1 \%)$ & $1(9.1 \%)$ & $8(72.7 \%)$ & $1(9.1 \%)$ & 2.82 \\
\hline CC10 & $1(9.1 \%)$ & $0(0 \%)$ & $7(63.6 \%)$ & $3(27.3 \%)$ & 3.09 \\
\hline Total & & & & 3.21 \\
\hline
\end{tabular}

Keterangan: $C C$ adalah Kode Item Pertanyaan
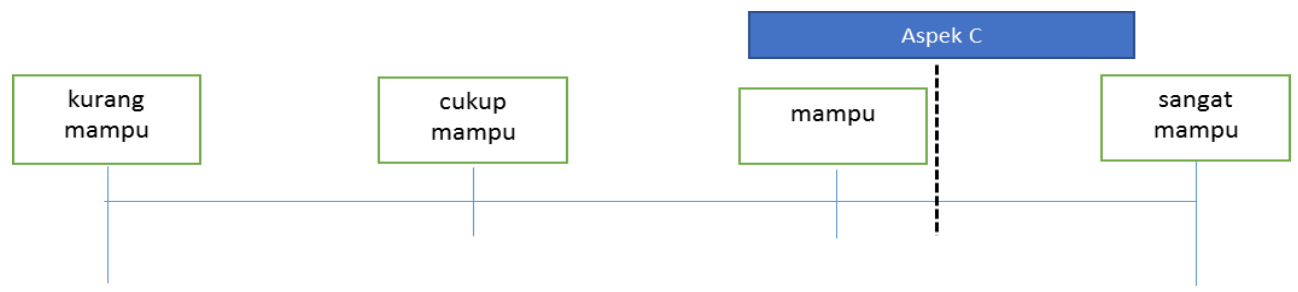

Gambar 3. Diagram Kemampuan Guru Pada Indikator 3

Item pertanyaan $\mathrm{CC} 1$ mempunyai rata-rata 3.18 , item pertanyaan $\mathrm{CC} 2$ mempunyai rata-rata 3.45 , item pertanyaan CC3 mempunyai rata-rata 3.27 , item pertanyaan CC4 mempunyai rata-rata 3.27, item pertanyaan CC5 mempunyai ratarata 3.27, item pertanyaan CC6 mempunyai rata-rata 3.27, item pertanyaan CC7 mempunyai rata-rata 3.36 , item pertanyaan $\mathrm{CC} 8$ mempunyai rata-rata 3.36 , item 
pertanyaan CC9 mempunyai rata-rata 2.82, item pertanyaan CC10 mempunyai rata-rata 3.09. Secara keseluruhan memiliki rata-rata sebesar 3.21 yang berarti dikategorikan baik.

\section{Menyelenggarakan pembelajaran yang mendidik}

Hasil penelitian indikator 4 yakni, menyelenggarakan pembelajaran yang mendidiksebagai berikut:

Tabel 4. Rekap Jawaban Kuesioner Indikator 4

\begin{tabular}{clllll}
\multicolumn{5}{c}{ Menyelenggarakan pembelajaran yang mendidik } \\
Item & TB & KB & B & SB & Mean \\
\hline DD1 & $0(0 \%)$ & $0(0 \%)$ & $3(27.3 \%)$ & $8(72.7 \%)$ & 3.73 \\
DD2 & $0(0 \%)$ & $1(9.1 \%)$ & $6(54.5 \%)$ & $4(36.4 \%)$ & 3.27 \\
DD3 & $0(0 \%)$ & $0(0 \%)$ & $9(81.8 \%)$ & $2(18.2 \%)$ & 3.18 \\
DD4 & $1(9.1 \%)$ & $8(72.7 \%)$ & $1(9.1 \%)$ & $1(9.1 \%)$ & 2.18 \\
DD5 & $1(9.1 \%)$ & $2(18.2 \%)$ & $7(63.6 \%)$ & $1(9.1 \%)$ & 2.73 \\
DD6 & $0(0 \%)$ & $8(72.7 \%)$ & $3(27.3 \%)$ & $0(0 \%)$ & 2.27 \\
DD7 & $0(0 \%)$ & $0(0 \%)$ & $4(36.4 \%)$ & $7(63.6 \%)$ & 3.64 \\
DD8 & $0(0 \%)$ & $0(0 \%)$ & $9(81.8 \%)$ & $2(18.2 \%)$ & 3.18 \\
DD9 & $0(0 \%)$ & $0(0 \%)$ & $9(81.8 \%)$ & $2(18.2 \%)$ & 3.18 \\
DD10 & $0(0 \%)$ & $2(18.2 \%)$ & $8(72.7 \%)$ & $1(9.1 \%)$ & 2.91 \\
Total & & & & & 3.03 \\
\hline
\end{tabular}

Keterangan: DD adalah Kode Item Pertanyaan

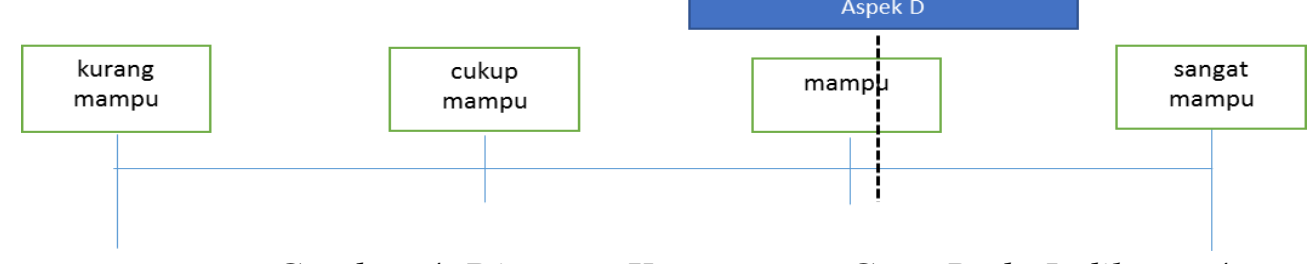

Gambar 4. Diagram Kemampuan Guru Pada Indikator 4

Item pertanyaan DD1 mempunyai rata-rata 3.73 , item pertanyaan DD2 mempunyai rata-rata 3.27, item pertanyaan DD3 mempunyai rata-rata 3.18 , item pertanyaan DD4 mempunyai rata-rata 2.18, item pertanyaan DD5 mempunyai rata-rata 2.73 , item pertanyaan DD6 mempunyai rata-rata 2.27 , item pertanyaan DD7 mempunyai rata-rata 3.64, item pertanyaan DD8 mempunyai rata-rata 3.18, item pertanyaan DD9 mempunyai rata-rata 3.18, item pertanyaan DD10 mempunyai rata-rata 2.91. Secara keseluruhan rata-rata 3.03 yang berarti dikategorikan baik. 


\section{Memanfaatkan teknologi informasi}

Hasil perhitungan indikator 5 mengenai memanfaatkan teknologi informasi dan komunikasi sebagai berikut:

Tabel 5. Rekap Jawaban Kuesioner Indikator 5

\begin{tabular}{llllll}
\multicolumn{6}{l}{ Memanfaatkan teknologi informasi } \\
Item & TB & KB & B & SB & Mean \\
\hline EE1 & $1(9.1 \%)$ & $9(81.8 \%)$ & $0(0 \%)$ & $1(9.1 \%)$ & 2.09 \\
EE2 & $1(9.1 \%)$ & $4(36.4 \%)$ & $5(45.5 \%)$ & $1(9.1 \%)$ & 2.55 \\
EE3 & $0(0 \%)$ & $2(18.2 \%)$ & $7(63.6 \%)$ & $2(18.2 \%)$ & 3.00 \\
EE4 & $0(0 \%)$ & $1(9.1 \%)$ & $8(72.7 \%)$ & $2(18.2 \%)$ & 3.09 \\
EE5 & $0(0 \%)$ & $1(9.1 \%)$ & $8(72.7 \%)$ & $2(18.2 \%)$ & 3.09 \\
Total & & & & & 2.76 \\
\hline
\end{tabular}

Keterangan: EE adalah Kode Item Pertanyaan

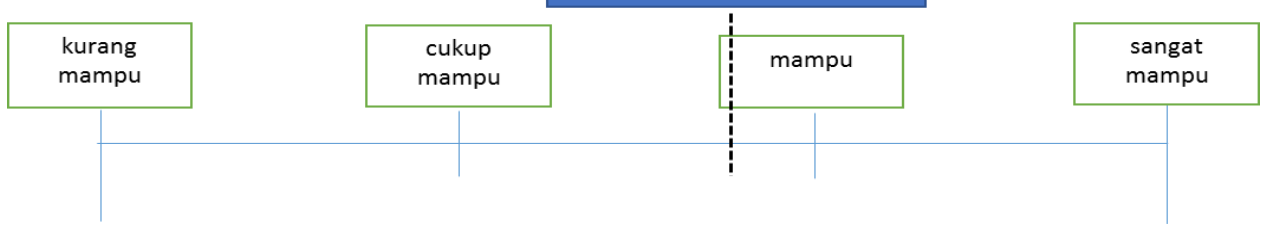

Gambar 5. Diagram Kemampuan Guru Pada Indikator 5

Item pertanyaan EE1 mempunyai rata-rata 2.09, item pertanyaan EE2 mempunyai rata-rata 2.55, item pertanyaan EE3 mempunyai rata-rata 3, item pertanyaan EE4 mempunyai rata-rata 3.09, item pertanyaan EE5 mempunyai ratarata 3.09, Secara keseluruhan untuk indikator dari aspek dalam memanfaatkan teknologi informasi memiliki nilai rata-rata sebesar aspek 2.76 yang berarti dikategorikan cukup atau tidak mampu.

Memfasilitasi pengembangan potensi peserta didik untuk mengaktualisasikan berbagai potensi yang dimiliki

Hasil penelitian pada indikator 6 aspek yang mengenai memfasilitasi pengembangan potensi peserta didik sebagai berikut:

Tabel 6. Rekap Jawaban Kuesioner Indikator 6

\begin{tabular}{|c|c|c|c|c|c|}
\hline \multicolumn{6}{|c|}{$\begin{array}{l}\text { Memfasilitasi pengembangan potensi peserta didik untuk } \\
\text { mengaktualisasikan berbagai potensi yang dimiliki }\end{array}$} \\
\hline Item & TB & $\mathrm{KB}$ & B & SB & Mean \\
\hline FF1 & $0(0 \%)$ & $0(0 \%)$ & $9(81.8 \%)$ & $2(18.2 \%)$ & 3.18 \\
\hline FF2 & $0(0 \%)$ & $0(0 \%)$ & $8(72.7 \%)$ & $3(27.3 \%)$ & 3.27 \\
\hline FF3 & $0(0 \%)$ & $1(9.1 \%)$ & $8(72.7 \%)$ & $2(18.2 \%)$ & 3.09 \\
\hline
\end{tabular}




\begin{tabular}{llllll} 
FF4 & $0(0 \%)$ & $1(9.1 \%)$ & $2(18.2 \%)$ & $8(72.7 \%)$ & 3.64 \\
FF5 & $0(0 \%)$ & $0(0 \%)$ & $9(81.8 \%)$ & $2(18.2 \%)$ & 3.18 \\
FF6 & $0(0 \%)$ & $0(0 \%)$ & $9(81.8 \%)$ & $2(18.2 \%)$ & 3.18 \\
FF7 & $0(0 \%)$ & $1(9.1 \%)$ & $8(72.7 \%)$ & $2(18.2 \%)$ & 3.09 \\
FF8 & $0(0 \%)$ & $1(9.1 \%)$ & $8(72.7 \%)$ & $2(18.2 \%)$ & 3.09 \\
FF9 & $0(0 \%)$ & $0(0 \%)$ & $9(81.8 \%)$ & $2(18.2 \%)$ & 3.18 \\
Total & & & & & 3.21 \\
\hline
\end{tabular}

Keterangan: FF adalah Kode Item Pertanyaan

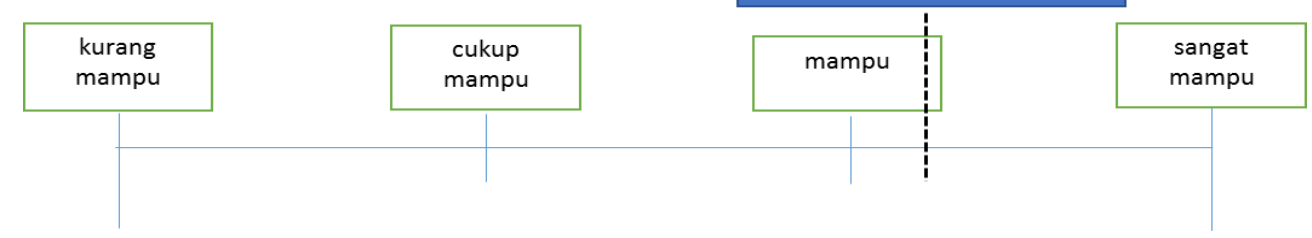

Gambar 6. Diagram Kemampuan Guru Pada Indikator 6

Item pertanyaan FF1 mempunyai rata-rata 3.18, item pertanyaan FF2 mempunyai rata-rata 3.27, item pertanyaan FF3 mempunyai rata-rata 3.09, item pertanyaan FF4 mempunyai rata-rata 3.64, item pertanyaan FF5 mempunyai ratarata 3.18, item pertanyaan FF6 mempunyai rata-rata 3.18, item pertanyaan FF7 mempunyai rata-rata 3.09, item pertanyaan FF8 mempunyai rata-rata 3.09, item pertanyaan FF9 mempunyai rata-rata 3.18. Secara keseluruhan pada indikator 6 memfasilitasi pengembangan potensi peserta didik untuk mengaktualisasikan berbagai potensi yang dimiliki memiliki rata-rata sebesar 3.21 yang berati dikategorikan baik.

\section{Berkomunikasi secara efektif, empatik dan santu dengan peserta didik}

Hasil penelitian pada indikator 7 yakni, kemampuan pedagogik dari aspek yang mengenai berkomunikasi secara efektif, empatik, dan santun sebagai berikut:

Tabel 7. Rekap Jawaban Kuesioner Indikator 7

\begin{tabular}{llllll}
\multicolumn{5}{c}{ Berkomunikasi secara efekti, empatik dan santu dengan peserta didik } \\
Item & TB & KB & B & SB & Mean \\
\hline GG1 & $0(0 \%)$ & $0(0 \%)$ & $9(81.8 \%)$ & $2(18.2 \%)$ & 3.18 \\
GG2 & $0(0 \%)$ & $0(0 \%)$ & $8(72.7 \%)$ & $3(27.3 \%)$ & 3.27 \\
GG3 & $0(0 \%)$ & $0(0 \%)$ & $8(72.7 \%)$ & $3(27.3 \%)$ & 3.27 \\
GG4 & $0(0 \%)$ & $0(0 \%)$ & $9(81.8 \%)$ & $2(18.2 \%)$ & 3.18 \\
GG5 & $0(0 \%)$ & $0(0 \%)$ & $9(81.8 \%)$ & $2(18.2 \%)$ & 3.18 \\
GG6 & $0(0 \%)$ & $0(0 \%)$ & $8(72.7 \%)$ & $3(27.3 \%)$ & 3.27 \\
GG7 & $0(0 \%)$ & $0(0 \%)$ & $9(81.8 \%)$ & $2(18.2 \%)$ & 3.18
\end{tabular}




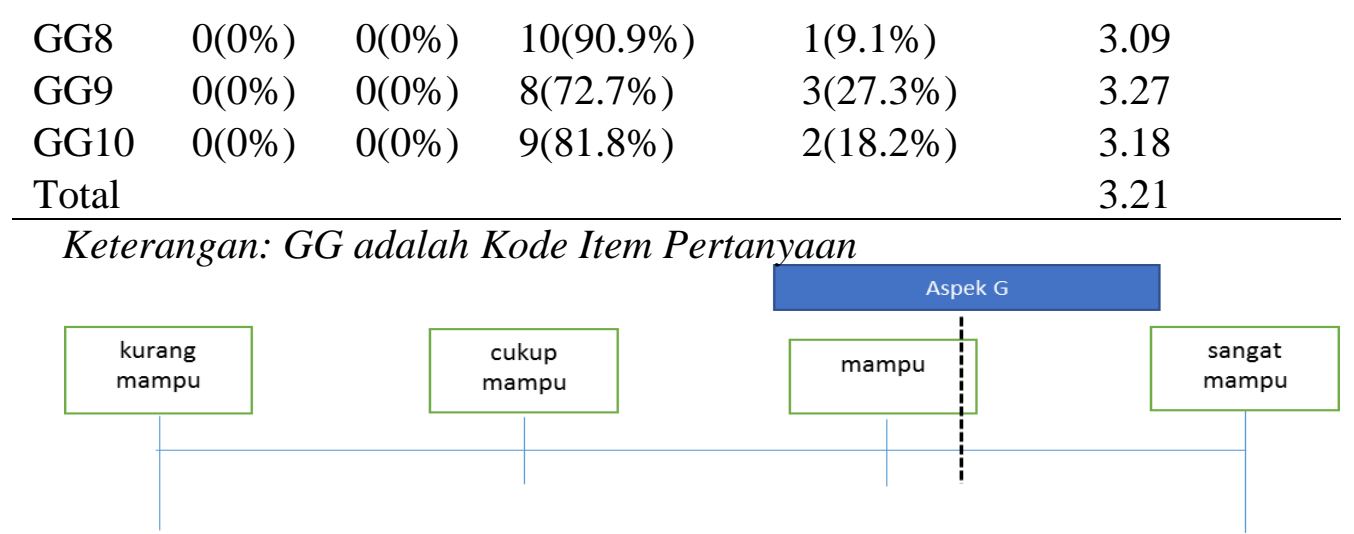

Gambar 7. Diagram Kemampuan Guru Pada Indikator 7

Item pertanyaan GG1 mempunyai rata-rata 3.18, item pertanyaan GG2 mempunyai rata-rata 3.27 , item pertanyaan GG3 mempunyai rata-rata 3.27 , item pertanyaan GG4 mempunyai rata-rata 3.18, item pertanyaan GG5 mempunyai rata-rata 3.18, item pertanyaan GG6 mempunyai rata-rata 3.27, item pertanyaan GG7 mempunyai rata-rata 3.18, item pertanyaan GG8 mempunyai rata-rata 3.09, item pertanyaan GG9 mempunyai rata-rata 3.27, item pertanyaan GG10 mempunyai rata-rata 3.18, Secara keseluruhan berkomunikasi secara efekti, empatik dan santun dengan peserta didik memiliki rata-rata sebesar 3.21 yang berarti dikategorikan baik.

\section{Menyelenggarakan penilaian dan evaluasi proses hasil belajar}

Hasil penelitian pada indikator 8 aspek mengenai kemampuan guru dalam menyelenggarakan penilaian dan evaluasi proses hasil belajar sebagai berikut:

Tabel 8. Rekap Jawaban Kuesioner Indikator 8

\begin{tabular}{|c|c|c|c|c|c|}
\hline \multicolumn{6}{|c|}{$\begin{array}{l}\text { Menyelenggarakan penilaian dan evaluasi proses hasil } \\
\text { belajar }\end{array}$} \\
\hline Item & $\mathrm{TB}$ & $\mathrm{KB}$ & B & SB & Mean \\
\hline HH1 & $0(0 \%)$ & $5(45.5 \%)$ & $1(9.1 \%)$ & $5(45.5 \%)$ & 3.00 \\
\hline HH2 & $0(0 \%)$ & $0(0 \%)$ & $6(54.5 \%)$ & $5(45.5 \%)$ & 3.45 \\
\hline HH3 & $0(0 \%)$ & $0(0 \%)$ & $1(9.1 \%)$ & $10(90.9 \%)$ & 3.91 \\
\hline HH4 & $0(0 \%)$ & $0(0 \%)$ & $7(63.6 \%)$ & $4(36.4 \%)$ & 3.36 \\
\hline Total & & & & & 3.43 \\
\hline
\end{tabular}

Keterangan: $\mathrm{HH}$ adalah Kode Item Pertanyaan
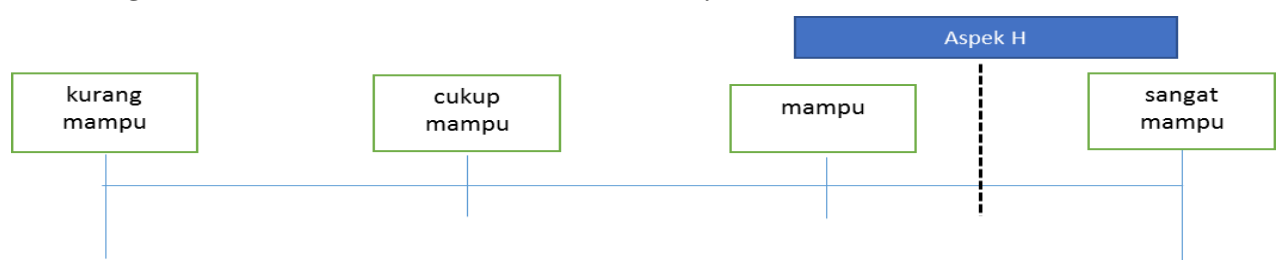


\section{Gambar 8. Diagram Kemampuan Guru Pada Indikator 8}

Item pertanyaan $\mathrm{HH} 1$ mempunyai rata-rata 3, item pertanyaan $\mathrm{HH} 2$ mempunyai rata-rata 3.45 , item pertanyaan $\mathrm{HH} 3$ mempunyai rata-rata 3.91 , item pertanyaan HH4 mempunyai rata-rata 3.36, Secara keseluruhan untuk indikator dari aspek menyelenggarakan penilaian dan evaluasi proses hasil belajar memiliki rata-rata sebesar 3.43 yang berarti dikategorikan baik.

\section{Memanfaatkan hasil penilaian dan evaluasi untuk kepentingan pembelajaran}

Hasil penelitian pada indikator 9 aspek kemampuan guru memanfaatkan hasil penilaian dan evaluasi untuk kepentingan pembelajaran sebagai berikut:

Tabel 9. Rekap Jawaban Kuesioner Indikator 9

\begin{tabular}{llllll}
\hline \multicolumn{5}{c}{ Memanfaatkan hasil penilaian dan evaluasi untuk kepentingan pembelajaran } \\
Item & TB & KB & B & SB & Mean \\
\hline II1 & $0(0 \%)$ & $6(54.5 \%)$ & $2(18.2 \%)$ & $3(27.3 \%)$ & 2.73 \\
II2 & $0(0 \%)$ & $6(54.5 \%)$ & $1(9.1 \%)$ & $4(36.4 \%)$ & 2.82 \\
Total & & & & & 2.78 \\
\hline
\end{tabular}

Keterangan: II adalah Kode Item Pertanyaan

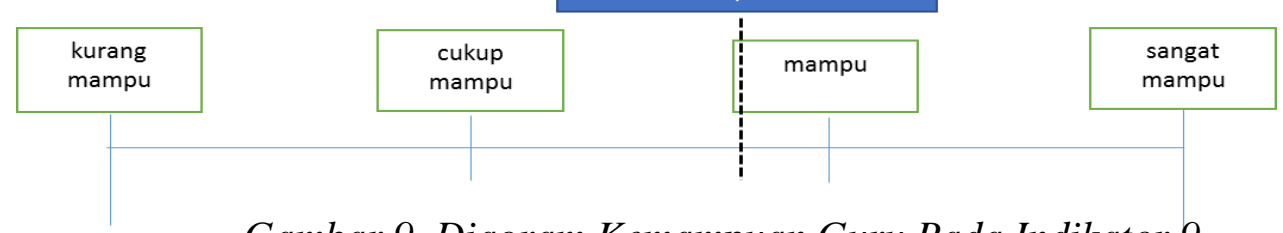

Gambar 9. Diagram Kemampuan Guru Pada Indikator 9

Item pertanyaan II1 mempunyai rata-rata 2.73 , item pertanyaan II2 mempunyai rata-rata 2.82, Secara keseluruhan untuk indikator dari aspek memanfaatkan hasil penilaian dan evaluasi untuk kepentingan pembelajaran memiliki rata-ratanilai sebesar 2.78. yang berarti dikategorikan baik.

\section{Melakukan tindakan reflektif untuk peningkatan kualitas pembelajaran}

Hasil penelitian pada indikator 10 aspek yang melakukan tindakan reflektif untuk peningkatan kualitas pembelajaran sebagai berikut:

Tabel 10. Rekap Jawaban Kuesioner Indikator 10

\begin{tabular}{llllll}
\multicolumn{6}{l}{ Melakukan tindakan reflektif untuk peningkatan kualitas pembelajaran } \\
Item & TB & KB & B & SB & Mean \\
\hline JJ1 & $0(0 \%)$ & $1(9.1 \%)$ & $7(63.6 \%)$ & $3(27.3 \%)$ & 3.18 \\
JJ2 & $0(0 \%)$ & $1(9.1 \%)$ & $7(63.6 \%)$ & $3(27.3 \%)$ & 3.18 \\
JJ3 & $0(0 \%)$ & $6(54.5 \%)$ & $3(27.3 \%)$ & $2(18.2 \%)$ & 2.64
\end{tabular}


Keterangan: JJ adalah Kode Item Pertanyaan

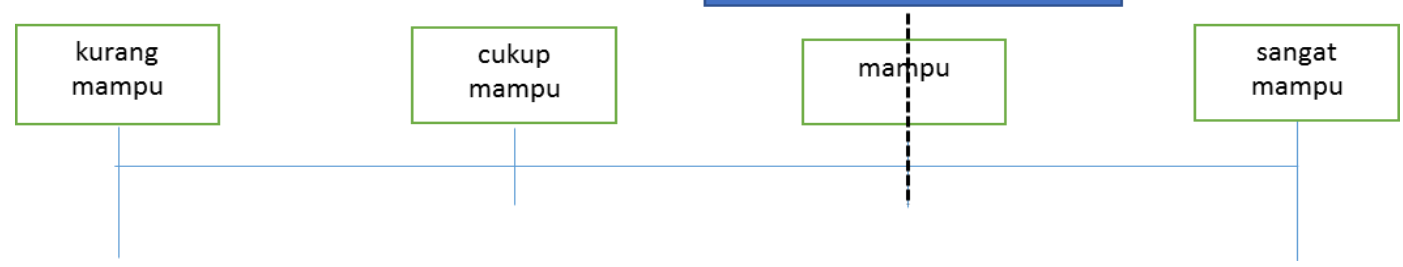

Gambar 10. Diagram Kemampuan Guru Pada Indikator 10

Item pertanyaan JJ1 mempunyai rata-rata 3.18 , item pertanyaan $\mathrm{JJ} 2$ mempunyai rata-rata 3.18 , item pertanyaan JJ3 mempunyai rata-rata 2.64 , Secara keseluruhan untuk indikator dari aspekmelakukan tindakan reflektif untuk peningkatan kualitas pembelajaran memiliki nilai rata-rata sebesar 3.00 yang berarti dikategorikan baik.

\section{SIMPULAN}

Hasil penelitian ini menunjukkan bahwa kemampuan pedagogik guru pada indikator: a) memahami karateristik peserta didik dari aspek fisik, moral, spiritual, sosial, kultural emosional, dan intelektual dikategorikan dengan rata-rata nilai 3,06 \% baik; b) menguasai teori belajar dan prinsip-prinsip pembelajaran dikategorikan baik dengan rata-rata nilai $3.25 \%$ baik; c) mengembangkan kurikulum terkait mata pelajaran yang diampu dikategorikan baik dengan rata-rata nilai 3,20\% baik; d) menyelenggarakan pembelajaran yang mendidik dengan ratarata nilai 3,03 \% baik; e) memanfaatkan teknologi informasi dan komunikasi dengan rata-rata nilai 2,76 \% kurang mampu; f) mengembangkan peserta didik untuk mengaktualisasikan berbagai potensi yang dimilikinyadengan rata-rata nilai 3.21 baik; g) berkomunikasi secara efektif, empatik, dan santun dengan rata-rata nilai 3,21 baik; h) menyelenggarakan penilaian dan evaluasi hasil belajar dengan rata-rata nilai 3.43 baik; i) Memanfaatkan hasil penilaian dan evaluasi 2.78baik; j) melakukan tindakan reflektif dengan rata-rata nilai 3,00 baik.

\section{DAFTAR PUSTAKA}

Dantes, N. (2012). Metode Penelitian. Yogyakarta: ANDI. 
Feralys, N. M. (2015). Kompetensi Guru Dalam Meningkatkan Prestasi Belajar Pada SMP Negeri Dalam Kota Banda Aceh. Jurnal Administrasi Pendidikan Pascasarjana Universitas Syiah Kuala, 45-67.

Herliani, M., \& Dhiniaty, G. (2015). Kompetensi Pedagogik Guru Dalam Implementasi Kurikulum 2013 SD Se-Kecamatan Kasihan Bantul Yogyakarta. PGSD Indonesia (Indonesian Primary Education Journal), 35-42.

Kemendikbud. (2012). Pengembangan Kurikulum 2013. Kementerian Pendidikan dan Kebudayaan. Jakarta.

Kemendikbud. (2013a). Kerangka Dasar dan Struktur Kurikulum 2013. Kementerian Pendidikan dan Kebudayaan. Jakarta.

Kusuma, D. C. (2013). “Analisis Komponen-Komponen Pengembangan Kurikulum 2013 pada Bahan Uji Publik Kurikulum 2013”. Jurnal Pendidikan: Universitas Pendidikan Indonesia.

Mustofa. (2007). Upaya Pengembangan Profesionlaisme Guru di Indonesia. Jurnal Ekonomi dan Pendidikan, 76-88.

Norsidi. (2018). Survei Kompetensi Pedagogik Guru Sekolah Dasar (SD) Dalam Mendukung Implementasi Kurikulum 2013 di Kabupaten Ketapang. Sosial Horizon, 76-90.

Suharsimi, A. (2006). Prosedur Penelitian Suatu Pendekatan Praktik. Jakarta: Rineka Cipta.

Uno, H. (2009). Profesi Kependidikan Problem, Solusi, dan Reformasi Pendidikan di Indonesia. Jakarta: Bumi Aksara.

Penelitian Kualitatif. Surakarta: Yuma Pustaka. 